\title{
Comparing 3DQRS and VCG approaches for ECG QRS detection within 1.5T, 3T and 7T MRI
}

\author{
Thomas S Gregory ${ }^{1 *}$, Ehud J Schmidt ${ }^{2}$, Shelley H Zhang ${ }^{2}$, Zion T Tse ${ }^{1}$ \\ From 17th Annual SCMR Scientific Sessions \\ New Orleans, LA, USA. 16-19 January 2014
}

\section{Background}

Electrocardiograms (ECGs) obtained within High-field MRIs are distorted due to the Magneto-hydrodynamic (MHD) effect. Blood plasma electrolytes ejected into the aorta during early systole interact with the strong magnetic field of the MR scanner to produce a MHD-induced voltage (VMHD) [1]. The VMHD overlay on ECG traces can result in intermittent QRS detection. Vectorcardiogram (VCG) based gating approaches have been conventionally adapted in most MRI scanners [2], but may fail at high field strengths [3]. Recently, a multiple ECG channel cross-correlation based algorithm, 3DQRS, has been developed to provide increased sensitivity levels in these environments [4]. The 3DQRS approach constructs a 3-D ECG representation, where the third dimension, in addition to voltage and time, is deemed a channels axis, formed from concurrent viewing of the precordial leads V1-V6. This study quantitatively compares 3DQRS and VCG approaches at a variety of MRI field strengths to assess the robustness of these methods.

\section{Methods}

12-lead ECG data was recorded using a prototype MRIconditional 12-lead ECG recorder [5] from 2 Premature Ventricular Contraction (PVC) patients, 2 Atrial Fibrillation $(\mathrm{AF})$ patients, and a healthy exercising athlete at $1.5 \mathrm{~T}$ and 3T [4]. A Halter recorder was used in 2 healthy volunteers at 7T [6] (Figure 1a-f). QRS detection was performed using a VCG-based approach (V1-V6, I, II) [2] and 3DQRS (V1-V6) using standard 12-lead ECG chest positioning [4]. Assessments of $3 \mathrm{DQRS}$ robustness relative to variations in field strength and cross-correlation kernel temporal length were performed (Figure 1g-h). False Positive (FP) and False Negative (FN) counts were recorded (total of 1,262 beats) in order to assess the sensitivity for QRS detection for each method at $1.5 \mathrm{~T}, 3 \mathrm{~T}$, and $7 \mathrm{~T}$.

\section{Results}

Table 1 shows the gating results for 3DQRS and VCG at $1.5 \mathrm{~T}, 3 \mathrm{~T}$, and $7 \mathrm{~T}$ in various subjects. 3DQRS subjectaveraged accuracy levels in QRS detection (False Negative), relative to VCG, were: $1.5 \mathrm{~T}$ (100\% vs. $96.6 \%)$, 3T (98.1\% vs. $87 \%)$, $7 \mathrm{~T}$ (96\% vs. $71.2 \%)$. In PVC patients at 1.5T, 3DQRS separated between the SR and PVC beats with $100 \%$ accuracy, whereas VCG falsely detected PVC beats, which were of similar length and magnitude to the sinus rhythm beats, with only $37.3 \%$ accuracy (Table 1 ).

\section{Conclusions}

The 3DQRS method represented a higher sensitivity in QRS detection than the VCG based approach, which resulted in decreased error levels in high field MRI.

\section{Funding}

NIH U41-RR019703, NIH R03 EB013873-01A1, SBIR-1

R43 HL110427-01.

\footnotetext{
${ }^{1}$ College of Engineering, University of Georgia, Athens, Georgia, USA
} Full list of author information is available at the end of the article 
(a) AF-patient \#1 (3T)

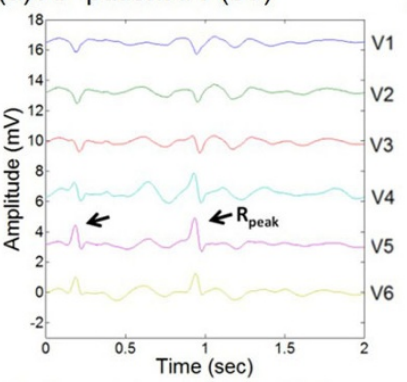

(d) Exercising Athlete (3T)

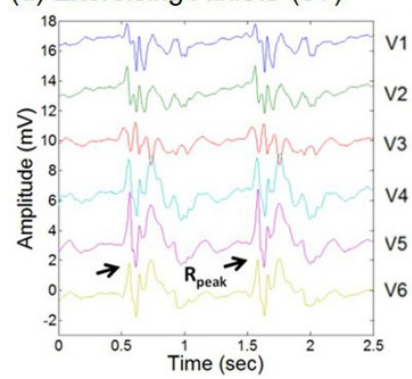

(b) AF patient \#2 (3T)

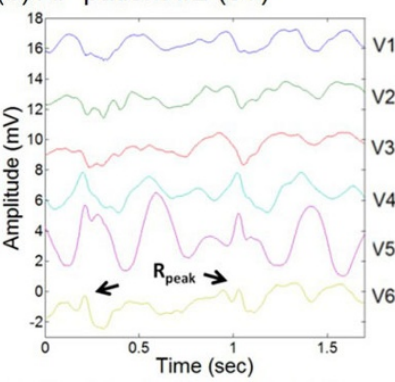

(e) Healthy Subject \#1 (7T) (c) PVC-patient (1.5T)

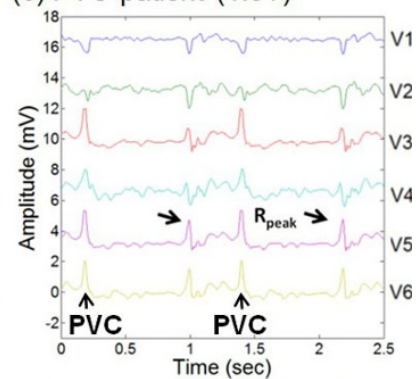

(f) Healthy Subject \#2 (7T)

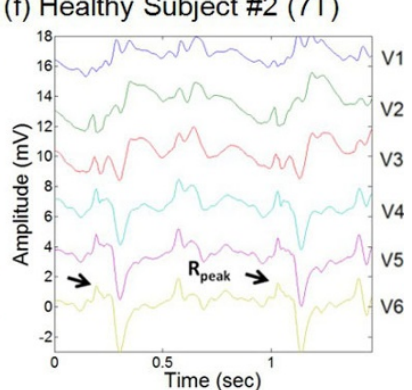

(g) Statistical correlation of intra-MRI QRS complex $(1.5,3 \& 7 T)$ to real QRS complex (OT) using the 3DQRS method

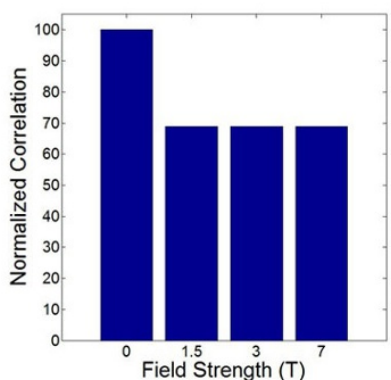

(h) Variation of 3DQRS for multiple field strengths with the temporal length of the QRS complex kernel utilized. A shorter length kernel allows for faster processing time.

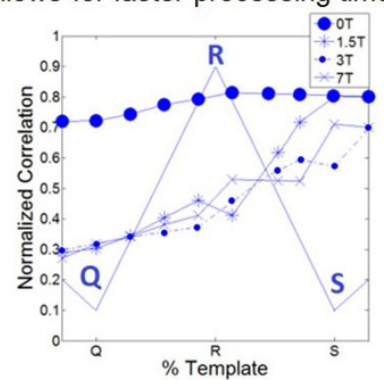

Figure 1 (a-f) Representative 2 cardiac cycles of the precordial leads V1-V6 for patients and volunteers at various field strengths ("Rpeak" denotes the R-wave peak positions). (g-h) 3DQRS performance evaluation, showing its performance at various field strengths.

Table 1 Results of 3DQRS and VCG Efficacy Tests at 1.5T, 3T, and 7T

\begin{tabular}{|c|c|c|c|c|c|c|}
\hline & \multirow{2}{*}{$\begin{array}{l}- \\
\text { False Negative }\end{array}$} & \multicolumn{2}{|c|}{ 3DQRS } & \multicolumn{2}{|c|}{ VCG-based } & \multirow[t]{2}{*}{ Marked } \\
\hline & & False Positive & False Negative & False Positive & Total Beats & \\
\hline \multirow[t]{2}{*}{$1.5 \mathrm{~T}$} & PVC at $1.5 T$ & 0 & 0 & 2 & 37 & 59 \\
\hline & Percent of Total & $0.0 \%$ & $0.0 \%$ & $3.4 \%$ & $62.7 \%$ & - \\
\hline \multirow[t]{6}{*}{$3 \mathrm{~T}$} & - & - & - & - & - & - \\
\hline & AF-Diagnosed \#1 at 3T & 3 & 1 & 3 & 6 & 45 \\
\hline & AF-Diagnosed \#2 at 3T & 1 & 1 & 34 & 18 & 169 \\
\hline & Exercising Athlete at 3T & 2 & 2 & 41 & 46 & 316 \\
\hline & Total Count & 6 & 4 & 41 & 46 & 316 \\
\hline & Percent of Total & $1.9 \%$ & $1.3 \%$ & $13.0 \%$ & $14.6 \%$ & - \\
\hline \multirow[t]{5}{*}{$7 \mathrm{~T}$} & - & - & - & - & - & - \\
\hline & Healthy Subject \#1 at 7T & 6 & 6 & 175 & 156 & 382 \\
\hline & Healthy Subject \#2 at 7T & 29 & 30 & 80 & 56 & 505 \\
\hline & Total Count & 35 & 36 & 255 & 212 & 887 \\
\hline & Percent of Total & $4.0 \%$ & $4.1 \%$ & $28.8 \%$ & $23.9 \%$ & - \\
\hline
\end{tabular}




\section{Authors' details}

${ }^{1}$ College of Engineering, University of Georgia, Athens, Georgia, USA.

${ }^{2}$ Brigham and Women's Hospital, Boston, Massachusetts, USA.

Published: 16 January 2014

\section{References}

1. Gupta: IEEE Trans Bio Med Eng 2008.

2. Fischer: MRM 1999.

3. Krug: JCMR 2013

4. Tse: JCMR 2013.

5. Tse: MRM 2013.

6. Krug: ComplnCardiol 2012.

doi:10.1186/1532-429X-16-S1-P148

Cite this article as: Gregory et al: Comparing 3DQRS and VCG

approaches for ECG QRS detection within 1.5T, 3T and 7T MRI. Journal

of Cardiovascular Magnetic Resonance 2014 16(Suppl 1):P148.

Submit your next manuscript to BioMed Central and take full advantage of:

- Convenient online submission

- Thorough peer review

- No space constraints or color figure charges

- Immediate publication on acceptance

- Inclusion in PubMed, CAS, Scopus and Google Scholar

- Research which is freely available for redistribution

Submit your manuscript at 